\title{
Comparison of the Antibacterial Effects of Nanosilver With 18 Antibiotics on Multidrug Resistance Clinical Isolates of Acinetobacter baumannii
}

\author{
Sarah Niakan ${ }^{1}$, Mohammad Niakan ${ }^{2, *}$, Saeed Hesaraki ${ }^{3}$, Mohammad Reza Nejadmoghaddam ${ }^{4}$, \\ Mohammad Moradi ${ }^{5}$, Mojtaba Hanafiabdar ${ }^{5}$, Roya Allamezadeh ${ }^{5}$, Meysam Sabouri ${ }^{4}$ \\ ${ }_{2}^{1}$ Faculty of Specialized Veterinary Medicine Sciences and Research Branch, Islamic Azad University, Tehran, IR Iran \\ 2 Department of Microbiology, Medicine Faculty, Shahed University, Tehran, IR Iran \\ 3 Department of Pathology, Faculty of Specialized Veterinary medicine Sciences and Research Branch, Islamic Azad University, Tehran, IR Iran \\ 4 Nanotechnology Research Center, School of Pharmacy Tehran university of Medical Sciences, Tehran, IR Iran \\ ${ }^{5}$ Nhahed university student`s Research committee, Medical Faculty, Tehran, IR Iran \\ *Corresponding author: Mohammad Niakan, Department of Microbiology, Shahed University, 31-Abdolazadeh St, Keshavarz Blvd, Post Cod: 1415635111, Tehran, IR Iran. Tel: +98- \\ 2188964792, Fax:+98-2188966310, E-mail: Niakan@shahed.ac.ir.
}

Received: September 30, 2012; Revised: February 10, 2013; Accepted: February 18, 2013

\begin{abstract}
Background:Acinetobacter baumannii plays a significant role in nosocomial infections. Multidrug-resistant A. baumannii is recognized to be among the most difficult antimicrobial-resistant Gram-negative bacilli to be controlled and treated. For this reason we examined the efficacy of nanosilver material with strong disinfectant properties against different types of bacteria.

Objectives: The purpose of this study was to examine the antibacterial activity of silver nanoparticles and compare them with some antibiotics against clinically isolated $A$. baumannii bacteria.

Materials and Methods: 60 A. baumannii strains were isolated from clinical specimens of university hospitals in Tehran province of Iran. The susceptibility test against 18 different antibiotics was investigated by disk diffusion methods. Colloidal nanosilver with about 6-34 $\mathrm{nm}$ particle size was prepared by chemical method. The minimum inhibitory concentration (MIC) and minimum bactericidal concentration (MBC) effect of nanosilver on A. baumannii were assessed at serially diluted nanosilver concentrations and compared to different antibiotics.

Results: The findings showed a 100\% resistance of A. baumannii to different antibiotics, including piperacillin, cefixime, ceftazidime, ceftizoxime, cephepim and clavulanat, and more than $90 \%$ resistance against imipenem, cefotaxime, ceftriaxone, ciprofloxacin and cotrimoxazole and lower resistance was seen against nitrofurantoin (62.8\%), gatifloxacin (56.85\%), levofloxacin (55.18\%), gentamycin (29.32\%), piperacillin/tazobactam (13.34\%), meropenem (13.16\%) and amikacin (12.07\%). MIC and MBC mean value of nanosilver dilutions were determined as $27.34 \mathrm{ppm}$ and $54.68 \mathrm{ppm}$, respectively. All isolates (100\%) were susceptible to more than MIC of nanosilver in contrast showed high resistance to multiple classes of antibiotics.

Conclusions: We conclude that nanosilver is a strong bactericidal agent to Multidrug resistant A. baumannii bacteria, so it can be useful to prevent a variety of nosocomial infections.
\end{abstract}

Keywords: Acinetobacter baumannii; Antibacterial; Emotions; MBC

\section{Background}

The genus Acinetobacter includes Gram-negative coccobacilli, with a DNA G+C content of 39 to $47 \mathrm{~mol} \%$, which are strictly aerobic, nonmotile, catalase positive and oxidase negative and has been divided into16 genome species $(1,2)$. Acinetobacter species are capable of colonizing and infecting human beings. They have been involved in a variety of nosocomial infectious diseases. Acinetobacter baumannii has become a particularly important organ- ism in the Intensive Care Unit (ICU) (3). Infections occur in the respiratory and urinary tract, peritoneum, surgical wounds, skin and eyes. Bacteremia and secondary meningitis with mortality rates from $20 \%$ to $27 \%$ were seen in several cases (1). They have been reported to be thecommon agents of nosocomial pneumonia, particularly ventilator-associated pneumonia(VAP) in hospital ICUs $(3,4)$. A.baumannii were shown to have the propensity to tolerate drying and resist multiple classes of antibiotics and

Implication for health policy/practice/research/medical education:

Acinetobacter baumannii play a significant role in nosocomial infections. Multidrug-resistant A. baumannii is recognized to be among the most difficult antimicrobial-resistant Gram-negative bacilli to control and treat. For this reason we examined the efficacy of nanosilver material with strong disinfectant properties against different types of bacteria. This Paper was the result of research on nanosilver products for prevention and treatment of some infectious disease.

Copyright (c) 2013, Ahvaz Jundishapur University of Medical Sciences; Licensee Kowsar Ltd. This is an Open Access article distributed under the terms of the Creative Commons Attribution License (http://creativecommons.org/licenses/by/3.0), which permits unrestricted use, distribution, and reproduction in any medium, provided the original work is properly cited. 
these are the key factors enabling the organism to survive and spread in the nosocomial environment. In general, the treatment of A. baumannii infections are often extremely difficult because of their widespread resistance to the major groups of antibiotics (1).

Resistance to antimicrobial agents by pathogenic bacteria has emerged in the recent years and is a major health problem. Nanosilver is one of the most commonly used nanomaterials due to its strong disinfectant properties (5); it has a much stronger germicidal capability which can kill up to 650 different types of bacteria (6). The inhibitory effect of ionic silver is due to several biological events such as attachment to cell membranes, alteration of membrane permeability through adsorption to the negatively charged bacterial cell wall, generating reactive oxygen species (ROS), and deactivating cellular enzymes (7). The American Biotech Labs have spent millions of dollars on testing the safety and efficacy of nanosilver technology products. All studies have concluded that nanosilver products are not toxic to cells, animals or humans (8). No toxic effects on human's tissues were reported by low concentration of nanosilver solutions (9).

\section{Objectives}

The purpose of this study was to examine the antibacterial activity of silver nanoparticles and compare them with some antibiotics against clinically isolated $A$. baumannii.

\section{Materials and Methods}

60 bacterial strains were isolated from clinical specimens. A. baumannii were isolated from wound, trachea, blood, sputum, pleura, urine and CSF from 8 hospitals in the Tehran province of Iran. All strains were isolated on the usual culture medium, Mueller-Hinton agar (Pronadisa Co. Italy), and after an overnight incubation at $35^{\circ} \mathrm{C}$, the differentiated test was used to detect the $\mathrm{A}$. bau mannii bacteria. The oxidative activity of isolated specimens was examined with biochemical by oxidase disk (Rosco Diagnostica A/S, Denmark). Biochemical capabilities of this organism were tested on TSI (Triple sugar iron agar) and LD (Lysine decarboxylase) media. The isolates were classified as A. baumannii species based on oxidative negative, non-fermenter and non-motile. A. baumannii produces colonies with a $2-3 \mathrm{~mm}$ diameter at 18-24 hours of incubation. A. baumannii did not produce acid from mannitol, sucrose and $\mathrm{H} 2 \mathrm{~S}$ on TSI media and had no reaction on lysine decarboxylase medium $(2,10)$.

Antimicrobial Effects of Different Antibiotics on A. baumannii Bacteria: The susceptibility test against 18 different antibiotics was investigated by the disk diffusion method according to the CLSI, 2010 guidelines (11), used as the reference method for antimicrobial susceptibility testing. Used Antibiotics: Amikacin, gentamycin, meropenem, piperacillin/tazobactam, gatifloxacin, levofloxacin, cotrimoxazole, nitrofurantoin, ciprofloxacin, imepenem, cefotaxime, ceftazidime, ceftizoxime, clavulanate, ceftriaxone, piperacillin, cefepime and cefixime. The Antimicrobial Effects of Nanosilver on A.baumannii: For preparation of nanosilver suspension; firstly silver nitrate was placed under the reducing effect of polyaldehyde, and thus Ag+ changed to metallic Ag after receiving an electron. Silver particles tend to accumulate together and to prevent this, an acrylic polymer was used in the presence of the surface water. The effect of this surface activator reduced the silver particles' tendency to stick. So a solution with silver particles in the nanometer size was obtained. To confirm the particle size, intensity test was performed on the solution. The average size of silver particles was 6-34 diameters.

MIC was defined as the lowest concentration of nanosilver preparation that prevented bacterial growth. MICs were determined for all strains by the CLSI reference method (11).Concentrations tested were serial twofold dilutions: 1 (3500 ppm), 1/2 (1750 ppm), 1/4 (875 ppm), 1/8 (437.5 ppm), 1/16 (218.75 ppm), 1/32 (109.37 ppm), 1/64 (54.68 ppm), 1/128 (27.34 ppm), 1/256 (13.67 ppm), 1/512 (6.83 ppm), 1/1024 (3.41 ppm). Disk diffusion tests were performed along with MIC determinations using one inoculum preparation. The MBCs were determined according to the methods outlined by the CLSI (11). The MBC was defined as the lowest concentration of compound that produced a $\geq 99.9 \%$ killing ( $\geq 3-\log 10$ ) drop in $\mathrm{CFU} / \mathrm{ml}$ compared to that of the starting inoculum. Two control samples were used to judge the validity of our work, one of them was free of nanosilver, and the other one was free from bacteria.

\section{Results}

We examined the A. baumannii growth in culture media in the presence of nanosilver compared to when the culture media contained different antibiotics; we found that nanosilver dilutions readily prevented growth of the multidrug resistant A.baumannii. The information about the susceptibility and resistance rate of the isolates against the 18 different antibiotics used is shown in Table 1 and Figures 1, 2, 3, 4. This information shows the $100 \%$ resistance of $A$. baumannii against different antibiotics such as piperacillin, cefixime, ceftazidime, ceftizoxime, cephepim and clavulanat, more than 90\% resistance against imipenem, cefotaxime, ceftriaxone, ciprofloxacin and cotrimoxazole, and lower resistance against nitrofurantoin (62.8\%), gatifloxacin (56.85\%), levofloxacin (55.18\%), gentamycin (29.32\%), piperacillin/ tazobactam (13.34\%), meropenem (13.16\%), and amikacin (12.07\%). Nanosilver examinations showed that the MIC of nanosilver was $27.34 \mathrm{ppm}$ (with average inhibition zone being $8.02 \mathrm{~mm}$ ), and the MBC was $54.68 \mathrm{ppm}$ (with average inhibition zone being $8.85 \mathrm{~mm}$ ). 
Table 1. The Susceptibility of A. baumannii Isolates Against Different Antibiotics

\begin{tabular}{|c|c|c|}
\hline & $\begin{array}{l}\text { Susceptibility } \\
\text { (\%) }\end{array}$ & $\begin{array}{l}\text { Average } \\
(\%)\end{array}$ \\
\hline \multicolumn{3}{|l|}{ Effects on Bacterial Cell Walls } \\
\hline$\beta$-lactams & - & 16.40 \\
\hline Penicillin & - & - \\
\hline Piperacillin & 0 & - \\
\hline Carbapenems & - & - \\
\hline Meropenem & 86.84 & - \\
\hline Imipenem & 1.5 & - \\
\hline Cephalosporins & - & - \\
\hline Cefixime & 0 & - \\
\hline Cefotaxime & 3.70 & - \\
\hline Ceftazidime & 0 & - \\
\hline Ceftriaxone & 1.72 & - \\
\hline Ceftizoxime & 0 & - \\
\hline Cephepim & 0 & - \\
\hline$\beta$-lactamas inhibitors & - & - \\
\hline Clavulanat & 0 & - \\
\hline Combinations & - & - \\
\hline Piperacillin/Tazobactam & 86.66 & - \\
\hline \multicolumn{3}{|c|}{ Effects on Bacterial Nucleic Acid } \\
\hline DNA replication inhibitors & - & 27.88 \\
\hline Fluoro quinolones & - & - \\
\hline Ciprofloxacin & 5.17 & - \\
\hline Levofloxacin & 44.82 & - \\
\hline Gatifloxacin & 43.15 & - \\
\hline \multicolumn{3}{|l|}{ Anaerobic DNA inhibitors } \\
\hline Nitrofuran- derivatives & - & - \\
\hline Nitrofurantoin & 37.20 & - \\
\hline \multicolumn{3}{|c|}{ DNA \& RNA Synthesis Inhibitors } \\
\hline Sulfonamides & - & - \\
\hline Cotrimoxazole & 9.09 & - \\
\hline \multicolumn{3}{|c|}{ Effects on Bacterial Protein Synthesis } \\
\hline Aminoglycosides & - & 79.30 \\
\hline 30 S Protein & - & - \\
\hline Amikacin & 87.93 & - \\
\hline Gentamycin & 70.68 & - \\
\hline
\end{tabular}

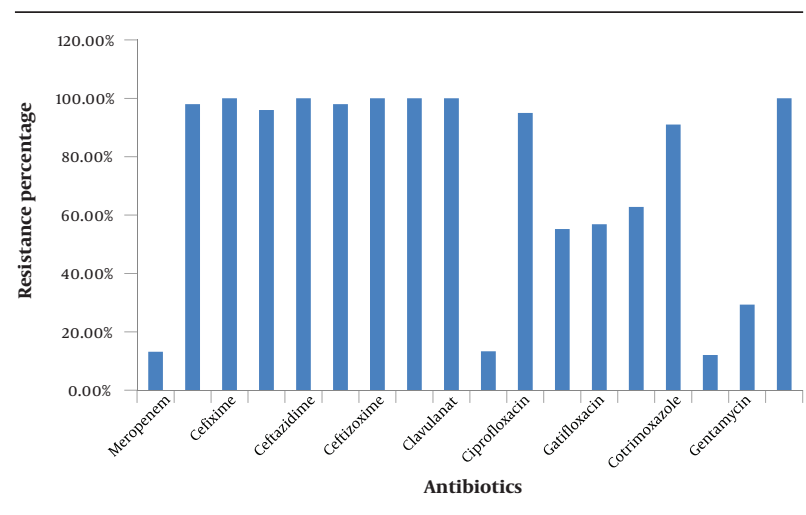

Figure 1. Resistance Percentage of A. baumannii to the Examined Antibiotics

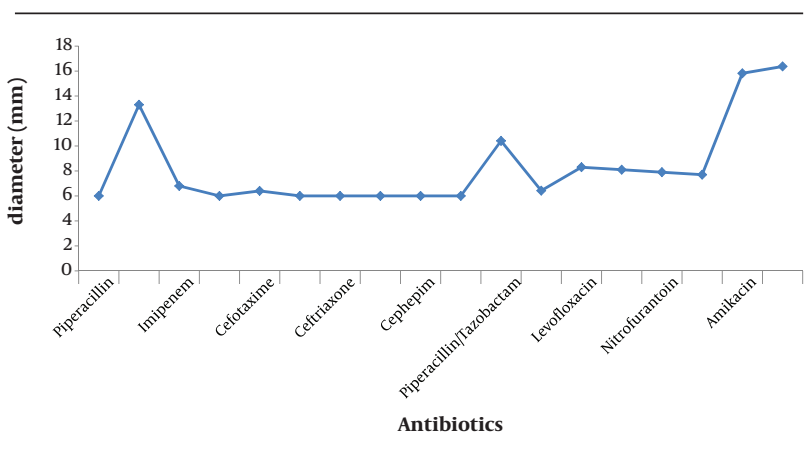

Figure 2. The Average Growth Inhibition Zone of Antibiotics

Susceptibility to nanosilver depended on the concentration. All isolates were susceptible to more than MIC of nanosilver compared to a high resistance to multiple classes of antibiotics. The Average of inhibition zone diameters of different concentrations of nanosilver dilutions is shown in Figure 3. By reducing the concentration of nanosilver, its effectiveness was reduced; at aboutthe 1/128 concentration and lower, inhibition zone of bacterial growth was not observed.

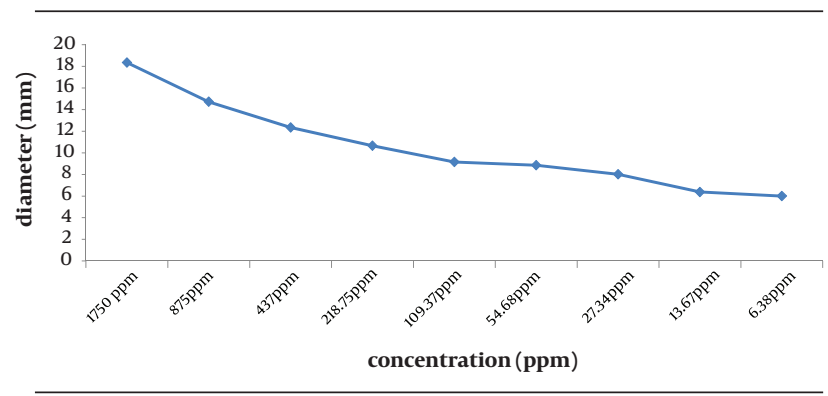

Figure 3. The Growth Inhibition Zone Average for Various Nanosilver Dilutions 


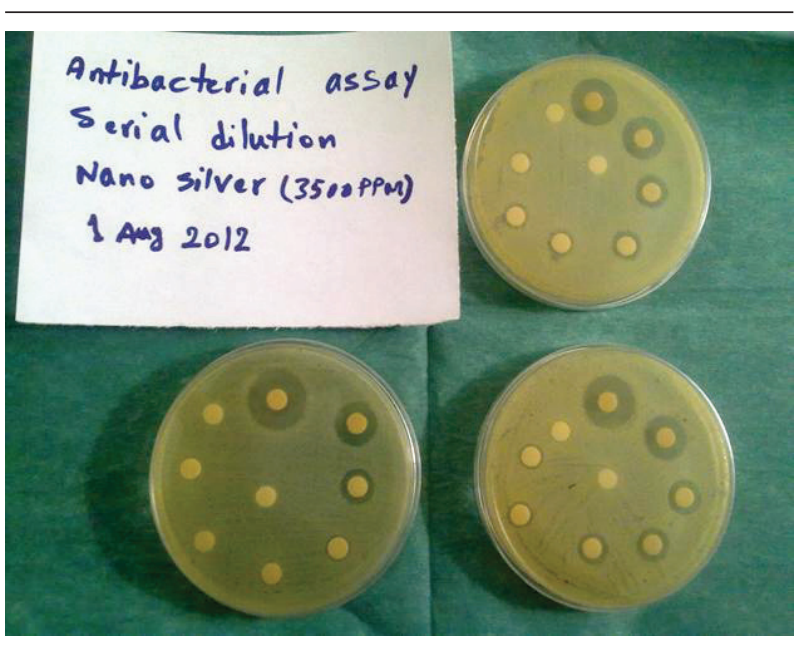

Figure 4. Antibacterial Disk Diffusion Test for Antibiotics

\section{Discussion}

The rising trend of resistance to antibiotics alarms about the dilemma that could be faced when treating such infections. The results showed that clinical isolates of $A$. baumannii in our hospitals are highly resistantto multiple classes of antibiotics. A. baumannii are important opportunistic pathogens with increasing rates of multi-antibiotic resistance due to both intrinsic and acquired mechanisms. In this study we collected 60 samples from different departments of eight university hospitals of Tehran. Several common antibiotics against A. baumannii were used for in vitro susceptibility test.

This experiment revealed high resistance rates of A.baumannii, which were as follows: $100 \%$ to piperacillin, cefixime, ceftazidime, ceftizoxime, cephepim, and clavulanat, more than $90 \%$ resistance to imipenem, cefotaxime, ceftriaxone, ciprofloxacin, and cotrimoxazole, more than $50 \%$ resistance to levofloxacin and gatifloxacin, low resistance to amikacin, meropenem, piperacillin/tazobactam and gentamycin. Other researches in Iran have also shown the high multidrug resistance rates of $A$. baumannii $(12,13)$. Other studies on A. baumannii have shown similar results with respect to these antibiotics (14-16). The resistance percentages reported by Gaur (17) against several antibiotics were different from ours including: ciprofloxacin (81\%), cefotaxime (79\%) ceftazidime (77.6\%), amikacin (74.8\%), imipenem(9.1\%) andmeropenem(9.8\%).

Other articles with different results include; the ghulam study (18), imipenem and meropenem (70\%), amikacin (52.5\%), ceftazidime, cefepime and ciprofloxacine (89\%). moniri (19) showed 60\% resistance against amikacin, ceftazidim, and ciprofloxacin. There is a common significance to all these articles and that is their alarming results about the high resistance of $A$. baumannii against many used antibiotics. For this reason we decided to find a safe, effective and accessible material with strong effects on pathogenic microorganism. Nanosilver colloid was made with chemical methods. Size dependent antimicrobial activity of silver nanoparticles has been reported for Gram-negative bacteria (20-22). Small nanoparticles with a large surface area to volume ratio provide a more efficient means for antibacterial activity even at very low concentrations. Silver nanoparticles (Diameter 5-32 nm) enhance the antibacterial activity of various antibiotics (23).

Silver nanoparticles anchor and penetrate the cell wall of Gram-negative bacteria $(21,24)$. The resultant structural change in the cell membrane could cause an increase in cell permeability, leading to an uncontrolled transport through the cytoplasmic membrane, and ultimately cell death. It has also been proposed that the antibacterial mechanism of silver nanoparticles is related to the formation of free radicals, and subsequent free radical-induced membrane damage (6). Ions move into the cells and lead to the production of reactive oxygen species. Based on the greater tendency of silver ions to strongly interact with thiol groups of vital enzymes and phosphorus-containing bases (25) and with the presence of silver nanoparticles inside the cells (21), it is likely that further damage could be caused by interactions with compounds such as the DNA.

This interaction may prevent cell division and DNA replication, and ultimately lead to cell death. In this study we examined the nanosilver efficacy against A. baumannii and its Minimum Inhibitory Concentration (MIC) and Minimum Bactericidal Concentration (MBC). Our results showed a 100\% influence by the prepared nanosilver and 27.34ppm MIC and 54.68ppm MBC. Numerous researches have been performed studying the effect of nanosilver on pathogenic microorganism, but there has not been any investigation on the effect of nanosilver on A.baumannii, and comparing its effects with different classes of antibiotics. Our resultswere quiet similar to the Humberto (26) study on Pseudomonas aeruginosa.

The MIC calculation for another gram negative bacteria, Escherichia coli, was reported later by Amany (27) and Petrus (28), which was similar to our results. In conclusion silver nanoparticle is a strong bactericide agent to the multidrug resistant $A$. baumannii strains, which is an important cause of hospital acquired infections. Thus, preparing new bactericidal agents in combination with nanosilver particles can be a useful route for introducing new antibiotics to prevent a variety of nosocomial infections. Finally, nanosilver products can be used for an effective prevention and treatment of some infectious diseases.

\section{Acknowledgements}

The authors are grateful to the Nano science research center, Shahed University, Farhood Najafi (Ph.D.) and Noor danesh medical laboratory, Mandana Ghadyani for 
fully supporting this work.

\section{Authors' Contribution}

None Declared.

\section{Financial Disclosure}

None Declared.

\section{Funding/Support}

Nano science research center, Shahed University and Noor-e-danesh medical laboratory supported this work.

\section{References}

1. Bergogne-Berezin E, Towner KJ. Acinetobacter spp. as nosocomial pathogens: microbiological, clinical, and epidemiological features. Clin Microbiol Rev. 1996;9(2):148-65.

2. Koneman EW, Allen DS, Janda M, Schreckenberger CP, Winn CW. Color atlas and textbook of diagnostic microbiology. Acinetobacter.Philadelphia:JB Lippincott Company;1992. p. 213-15.

3. Jung JY, Park MS, Kim SE, Park BH, Son JY, Kim EY, et al. Risk factors for multi-drug resistant Acinetobacter baumannii bacteremia in patients with colonization in the intensive care unit. BMC Infect Dis. 2010;10:228.

4. Rahbar M, Hajia M. Detection and quantitation of the etiologic agents of ventilator-associated pneumonia in endotracheal tube aspirates from patients in Iran. Infect Control Hosp Epidemiol. 2006;27(8):884-5.

5. Chen D, Xi T, Bai J. Biological effects induced by nanosilver particles: in vivo study. Biomed Mater. 2007;2(3):S126-8.

6. Kim JS, Kuk E, Yu KN, Kim JH, Park SJ, Lee HJ, et al. Antimicrobia effects of silver nanoparticles. Nanomedicine. 2007;3(1):95-101.

7. El-Ansary A, Al-Daihan S. On the toxicity of therapeutically used nanoparticles: an overview. J Toxicol. 2009;2009.

8. Moeller K. Nano-Silver Proven Safe for Humans, American Biotech Labs. 2009; Available from: http://www.healthfreedomusa. org.

9. Panyala Nagender Reddy, Peña-Méndez Eladia María, Havel Josef. Silver or silver nanoparticles: a hazardous threat to the environment and human health. J. Appl. Biomed. 2008;6(3):117-129.

10. Constantiniu Sofia, Romaniuc Angela, Iancu Luminița Smaranda, Filimon Raluca, Tarași Iuliana. Cultural and biochemical characteristics of Acinetobacter spp. Strains isolated from hospital units. J Prevent Med. 2004;12:35-42.

11. Performance standards for antimicrobial susceptibility testing; Twentieth informational supplement; M100-S20. 2010; Available from: http://www.idsociety.org/Antimicrobial_Susceptibility_Testing/.

12. Abbasi F, Yadegarynia D, Mardani M, Frasinejad B, Yaghubi T, Gholamin S. Emerging multi drug-resistant Acinetobacter in Iran: Study of 800 cases. Int J Infect Dis. 2010;14:e36

13. Vahdani Parviz, Yaghoubi Tofigh, Aminzadeh Zohreh. Hospital acquired antibiotic-resistant Acinetobacter baumannii infections in a 400-bed hospital in Tehran, Iran. Int J Prevent Med. 2011;2(3):127.

14. Henwood CJ, Gatward T, Warner M, James D, Stockdale MW,
Spence RP, et al. Antibiotic resistance among clinical isolates of Acinetobacter in the UK, and in vitro evaluation of tigecycline (GAR-936). JAntimicrob Chemother. 2002;49(3):479-87.

15. Manikal VM, Landman D, Saurina G, Oydna E, Lal H, Quale J. Endemic carbapenem-resistant Acinetobacter species in Brooklyn, New York: citywide prevalence, interinstitutional spread, and relation to antibiotic usage. Clin Infect Dis. 2000;31(1):101-6.

16. Medic D, Ukropina MM, Gusman V, Jelesic Z, Milosavljevic B. [Carbapenems resistance of Acinetobacter spp strains isolated from wound swabs during 2009-2010]. Med Pregl. 2011;64(11-12):583-7.

17. Gaur A, Garg A, Prakash P, Anupurba S, Mohapatra TM. Observations on carbapenem resistance by minimum inhibitory concentration in nosocomial isolates of Acinetobacter species: an experience at a tertiary care hospital in North India.J Health Popul Nutr. 2008;26(2):183-8.

18. Dhabaan GhN, Hamimah H, Shorman MA. Emergence of extensive drug-resistant Acinetobacter baumannii in North of Jordan. African J Microbiol Res. 2011;5(9):1070-5.

19. Moniri R, Farahani RK, Shajari G, Shirazi MN, Ghasemi A. Molecular epidemiology of aminoglycosides resistance in acinetobacter spp. With emergence of multidrug-resistant strains. Iran J Public Health. 2010;39(2):63-8.

20. Baker C, Pradhan A, Pakstis L, Pochan Darrin I, Shah S Ismat. Synthesis and antibacterial properties of silver nanoparticles. $\mathrm{J} \mathrm{Na}$ nosci nanotechnol. 2005;5(2):244-249.

21. Morones JR, Elechiguerra JL, Camacho A, Holt K, Kouri JB, Ramirez JT, et al. The bactericidal effect of silver nanoparticles. Nanotechnology. 2005;16(10):2346-53.

22. Panáček Aleš, Kvitek Libor, Prucek Robert, Kolar Milan, Vecerova Renata, Pizurova Nadezda, et al. Silver colloid nanoparticles: synthesis, characterization, and their antibacterial activity. J Phys Chem B. 2006;110(33):16248-16253.

23. Shahverdi AR, Fakhimi A, Shahverdi HR, Minaian S. Synthesis and effect of silver nanoparticles on the antibacterial activity of different antibiotics against Staphylococcus aureus and Escherichia coli. Nanomedicine. 2007;3(2):168-71

24. Sondi I, Salopek-Sondi B. Silver nanoparticles as antimicrobial agent: a case study on E. coli as a model for Gram-negative bacteria.J Colloid Interface Sci. 2004;275(1):177-82.

25. Hatchett David W, White Henry S. Electrochemistry of Sulfur Adlayers on the Low-Index Faces of Silver. $J$ Phys Chem. 1996;100(23):9854-9859.

26. Lara Humberto H, Ayala-Núnez Nilda V, Ixtepan Turrent Liliana del Carmen, Rodríguez Padilla Cristina. Bactericidal effect of silver nanoparticles against multidrug-resistant bacteria. World J Microbiol Biotechnol. 2010;26(4):615-621.

27. Amany A, El-Rab Sanaa F Gad. Effect of reducing and protecting agents on size of silver nanoparticles and their anti-bacterial activity. Der Pharma Chemica, 2012;4(1):53-65.

28. Petrus EM, Tinakumari S, Chai LC, Ubong A, Tunung R, Elexson $\mathrm{N}$, et al. A study on the minimum inhibitory concentration and minimum bactericidal concentration of Nano Colloidal Silver on food-borne pathogens. Int Food Res J. 2011;18:55-66.

Please cite this paper as: Niakan S, Niakan M, Hesaraki S, Nejadmoghaddam MR, Moradi M, Hanafiabdar M, et al Comparison the Antibacterial Effects of nanosilver With 18 Antibiotics on Multidrug Resistance Clinical Isolates of Acinetobacter baumannii. Jundishapur J Microbiol. 2013;6(5):e8341. DOI:10.5812/jjm.8341 